\title{
Understanding loyalty in multichannel retailing: the role of brand trust and brand attachment
}

\author{
Marta Frasquet \\ Alejandro Mollá Descals \\ Maria Eugenia Ruiz-Molina \\ Marketing Department, Universidad de Valencia, Valencia, Spain
}

\begin{abstract}
Purpose. The purpose of this paper it to understand loyalty in the multichannel retail context. The paper analyses the interplay between offline and online loyalty and the direct and indirect effects on loyalty of brand trust and brand attachment, in a cross-cultural study.
\end{abstract}

Design/methodology/approach. Online survey answered by 761 multichannel apparel shoppers in two countries (UK and Spain). SEM multigroup analysis is performed to test the hypothesized relations and the role of culture as a moderating variable.

Findings. Online loyalty is largely driven by offline loyalty, which is also positively affected by brand trust and brand attachment. These relationships hold across the two different cultures.

Research limitations/implications. The findings confirm the validity of applying the theory of cognitive dissonance to explain multichannel shopping behaviours. We did not find culture affects the relationships in our model; however, the validity of these findings should be tested considering other cultural variables different from nationality.

Practical implications. Multichannel retailers should focus on building trust and attachment towards the brand if they want to get online and offline loyalty. The efforts to build stronger bonds between the customer and the retail brand translate into higher loyalty, particularly towards the offline channels.

Originality/value. This paper extends the literature on the interactions between online and offline behaviour by focusing on the power of the brand to build strong customer bonds. Our model considers the role of brand attachment together with brand trust in offline and online loyalty simultaneously. 
Keywords: multichannel retailing, online loyalty, offline loyalty, brand trust, brand attachment.

Article Classification: Research paper

Aknowledgments: This research if part of the Project ECO2014-55881-R. 


\section{Introduction}

Over the last years, many retailers, irrespective of size, have added an online channel so becoming multichannel retailers. Initially the online channel was implemented and run as a separate division, but today channel coordination and integration is a priority for retailers (Herhausen et al., 2015), signaling the move from a multichannel to an omnichannel retailing model (Verhoef et al., 2015). Retailers expect to achieve benefits from the substantial investment of implementing multichannel distribution. There is some evidence that multichannel customers provide higher revenues (Kushwaha and Shankar, 2013), and are more loyal because the increased portfolio of services increases satisfaction (Wallace et al., 2004). However the bases of loyalty in the multichannel world are far from established, and multichannel retail managers are concerned about how stronger customer loyalty can be built through the combination of offline and online channels.

Multichannel retailers, in contrast to pure online retailers, have the opportunity to benefit from the interplay between offline and online behaviours to build customer loyalty. The interaction between offline and online customer's beliefs, attitudes and behaviours have been explored in recent research (e.g. Badrinarayanan et al., 2012; Kuan and Bock, 2007; Hahn and Kim, 2009; Kwon and Lennon, 2009a; 2009b; Jones and Kim, 2010), with a strong focus on the transference of offline trust to the online context. Our paper continues and extends this research theme by focusing on the power of the customer brand relationship to build loyalty in the multichannel context. In recent years, the brand building efforts of retailers have stimulated a research line around the retailer as a brand (Burt and Davies, 2010; Das, 2014a; 2015; Khan and Rahman, 2016). Building strong brand connections with customers is a solid basis for cultivating loyalty behaviours (Swoboda et al., 2013). Brand trust has been recognized as an antecedent of loyalty in the online context (Huang et al., 2014; Sahi et al., 2016). We extend the influence of the brand by analyzing the variable brand attachment. This has not been considered previously in the multichannel context, however due to the strong bonds that brand attachment implies (Park et al., 2010) we believe it can play a significant role in the multichannel context where loyalty is a challenge. An additional contribution of our research is analyzing the influence of those brand related variables on offline and online loyalty simultaneously. As Hsieh et al. 
(2012) point out, the determinants of loyalty have been studied in either the online or the offline context, but there is limited research on customer loyalty considering both channels simultaneously. The aim of this paper is to investigate how a strong customer brand relationship can benefit the multichannel retailer by building offline and online loyalty. Specifically, this paper aims to analyse the differential impact of brand trust and brand attachment on loyalty to each channel, and how offline loyalty transfers to online loyalty. Our model is tested in the apparel sector in two countries, Spain and UK, which allows us to analyse the moderating role of culture. The apparel sector was deemed the best context for our investigation. Many of the most dynamic, prolific and successful international retailers are apparel retailers. They are leading growth in online sales thanks in large part to channel integration and brand building efforts (Euromonitor International, 2014). This sector is led by firms that have built a brand with global appeal (Millward Brown, 2014), and manage combinations of channels to reach multiple consumer segments in different markets (Schröder, 2015).

Following this introduction, section 2 discusses the nature of the interaction between the offline and online channels of multichannel retailers and the relevance of the customer-brand relationship in this context. The variables of this research model then are defined and the relationships between them are justified. Section 3 explains the methodology of the study. Section 4 discusses the results, and section 5 presents the conclusions, managerial implications and future research directions.

\section{Theoretical framework and hypotheses}

Figure 1 shows the relationships among the focal constructs that act as drivers of offline and online loyalty for multichannel retailers. Our research model has its foundations on cognitive dissonance theory (Festinger, 1957). This theory argues that when a consumer is faced with new stimuli from an object that is inconsistent with his/her existing cognitions about the object, a state of dissonance is created. One of the mechanisms to reduce the discomfort of that dissonance is to transfer the existing cognitions to the new stimuli. In the multichannel retail context, this theory will suggest that as shoppers want to keep consistency in their beliefs and attitudes, they will transfer their existing attitudes and beliefs towards the offline channel of a retailer to its online channel (new stimuli). Specifically this means, first, that offline loyalty will drive online loyalty, and second, that retail brand 
trust and attachment, which are built in great part from the offline network (Bock et al., 2012) will have a direct and indirect influence on online loyalty. The model controls for two types of variables: shopping motivations (i.e. hedonic orientation and product involvement) and technology acceptance model (TAM) variables (ie. ease-of-use and usefulness).

INSERT FIGURE 1 ABOUT HERE

\subsection{Interaction between offline and online channels}

\subsubsection{Offline loyalty and online loyalty}

Loyalty is a key relational outcome in business to consumer relationships. Dick and Basu's (1994) definition: "the strength of the relationship between an individual's relative attitude and repeat patronage" (p.99), captures the attitudinal and behavioural components of loyalty. Building loyalty towards the retailer is a critical defensive strategy with the advent of e-retailing (Das, 2014b). Drawing from the conceptualization of loyalty, researchers have established the differences between online and offline loyalty (Danaher et al., 2003), and since the seminal study of Srinivasan et al. (2002), many researchers have investigated the determinants of online loyalty (e.g. Shankar et al., 2003; Kwon and Lennon, 2009b; Khan and Rahman, 2016). The meta-analysis of Toufauly et al. (2013) classified five types of determinants of online loyalty, and our study focuses on the customer's characteristics and perceptions type. Rather than looking specifically at online loyalty, we follow the cognitive dissonance theory that supports a line of research that focuses on the interaction effects between online and offline channels (e.g. Badrinarayanan et al., 2012; Kwon and Lennon, 2009a, 2009b; Jones and Kim, 2010; Fernández-Sabiote and Román, 2012).

As many shoppers are now migrating online to shop, it seems reasonable to expect that offline behavioural patterns transfer to the online channel. There is some evidence suggesting that a link between offline loyalty and online loyalty exists. Balabanis and Reynolds (2001) found that attitudes towards the retailer's brand have a positive effect on attitudes towards the online channel of the retailer. Kim and Park (2005) talk about consumer channel extension to refer to how consumers' attitude towards an offline retailer transfers to attitude towards the online channel of the retailer. In the context of grocery retailing, Rafiq and Fulford (2005) find support to the double jeopardy model's 
prediction that market leaders benefit disproportionately from loyalty transference from the offline to the online setting. In the banking sector, Van Birgelen et al. (2006) revealed interaction effects between satisfaction with the offline channel and the online channel. In the same sector, FernándezSabiote and Román (2012) extend those findings to show that offline service evaluations affect online evaluations and they interact to build loyalty towards the multichannel bank. The study of Farag et al. (2007) confirms the synergies between channels since they find that the frequency of in-store purchasing is related to the frequency of online purchasing and that the frequency of online searching is related to the frequency of in-store purchasing. Jones and Kim (2010), supported also on the theory of cognitive dissonance, confirm the strong relationship between offline patronage and online shopping intention. Thus, there are arguments to believe that when a customer has built loyalty to the offline channel of a retailer it is likely to transfer his/her positive attitude and behaviour to the online channel of the retailer, and accordingly our first hypothesis states:

H1: The greater the loyalty to the offline channel the greater the loyalty towards the online channel of the multichannel retailer.

\subsubsection{Retail brand trust}

Brand trust is defined as the willingness of a consumer to rely on a brand because of expectations that it will perform its function or will cause positive outcomes (Chaudhuri and Holbrook, 2001). In line with the emergent literature analysing cross channel synergies (e.g. Badrinarayanan et al., 2012; Kwon and Lennon, 2009a, 2009b; Jones and Kim, 2010), it may be assumed that for a multichannel retailer, brand trust largely depends on existing attitudes and beliefs built from prior experiences with the offline stores as well as the emergent expectations based on the online operation.

In line with the pivotal role of trust in building and maintaining relationships, the literature on the relational outcomes of trust is abundant. The role of trust is based on trust mitigating risks and uncertainty in a business relationship. In the offline retail context researchers have confirmed the link between trust in the retailer and loyalty in several settings (e.g. Sirdeshmukh et al., 2002; Guenzi et al., 2009; Sun and Lin, 2010). Thus, it seems there is enough evidence to pose the second hypothesis: 
H2: The greater the retail brand trust the greater the loyalty towards the offline channel of the multichannel retailer.

The emergence of the online channel awoke a research interest around the importance of trust for shopping over the Internet (Sahi et al., 2016). Most of the papers have dealt with trust in the online seller, assessing its drivers and consequences. There is an overall agreement on the relevance of building trust for increasing online sales. In this context Jarvenpaa et al. (1999) develop a model of antecedents and consequences of trust in an Internet store, and Gefen et al. (2003) demonstrate that online trust is as important as the widely accepted TAM variables (ease-of-use and perceived usefulness) to explain online purchase intention. More recently, Das (2016) confirms that trust in the online retailer positively influences purchase intentions, recommendation, and repurchase, and Khan and Rahman (2016) confirm that the brand trust developed through positive brand experiences, encourages loyalty towards the online retailer.

In the multichannel retail environment, shoppers are more likely to trust a retail brand that they can experience offline (Bock et al., 2012). There are a handful of papers investigating the link between retail brand trust and behavioural intentions for multichannel retailers, most of them applied to the apparel sector. Hahn and Kim (2009) hypothesized a direct link between trust in the offline store and intention to purchase online, but could only prove indirect links through confidence in the online store and online search intention. Badrinarayanan et al. (2012) show that purchase intentions in online stores of multichannel retailers are influenced by the transference of trust from the retailers' offline business. For experience goods such as apparel, where the shopper is unable to evaluate the quality and fit of a garment online, it is expected that the brand plays an important role to drive online purchases as it reduces the perceived risks of buying online. In this sector, Jones and Kim (2010) found that brand trust influences intentions to shop at the retailer's website. Accordingly:

H3: The greater the retail brand trust the greater the loyalty towards the online channel of the multichannel retailer. 


\subsubsection{Retail brand attachment}

The concept of attachment was initially investigated in the context of mother-child relationships and defined as an emotion-laden target-specific bond between a person and a specific object (Bowlby, 1979). Attachment implies a variety of emotions that Thomson et al. (2005) attempted to collect in their scale of brand attachment, which resulted in the identification of three dimensions: affection, passion and connection. Park et al. (2010) argue that any attempt to capture all possible emotions can leave some out, so they opt to develop a scale not including emotions as indicators of brand attachment. They also believe that attachment is more than emotions, as it includes cognitive representations that the individual develops about the brand, and define brand attachment as "the strength of the bond connecting the brand with the self" (p.2). Following Park's et al. (2010) conceptualization of brand attachment and applying it to the retail context, retail brand attachment would reflect the emotional and cognitive ties between a customer and a retailer.

It can be argued that multichannel retailers, compared to single channel retailers, are in a privileged position to develop strong customer attachment to their brands thanks to the synergies between channels. Interestingly, Keller (2010) contends that attachment involves a sense of community that is experienced when customers engage with other people connected with the brand, that is, employees or other customers. Physical stores are able to create a sense of friendship and community with salespeople that may impact the customer-brand relationship. Dolbec and Chebat (2013) found that flagship stores, due to the powerful brand experiences they enable, have a strong impact on brand attachment.

Given the strong relational bonds that brand attachment implies it is expected that brand attachment predicts the intentions of shoppers to engage with the brand. Thomson et al. (2005) proved the link between brand attachment and brand loyalty and the willingness to pay a price premium. Park et al. (2010) found that attachment to a brand explains the willingness to engage in more difficult behaviours in relation to purchasing or recommending the brand. In the retailing context, Huang et al. (2014) proved that brand attachment has a positive impact on attitudinal and behavioural loyalty. Hence: 
H4: The greater the retail brand attachment the greater the loyalty towards the offline channel of the multichannel retailer.

Similarly, in the multichannel environment, it is believed that the ability of a retailer to engage customers in personal and intimate relationships with the brand can increase customer loyalty (Jones and Kim, 2010). Kwon and Lennon (2009a) proved that there are interactions between brand attitudes and online and offline purchase intentions. To the best of our knowledge, no prior study has analysed the effect of brand attachment on online loyalty, but, extending prior research in the offline context, it may be argued that brand attachment will have a strong positive impact in online loyalty as attachment indicates a type of bond that increases the proneness to stay close to a brand. Online channels have the potential to impact brand attachment through activities that connect customers to provide a sense of community and emotional rewards (Keller, 2010). Thus:

H5: The greater the retail brand attachment the greater the loyalty towards the online channel of the multichannel retailer.

It may be suggested that consumers will be more attached to trusted brands. When a shopper trusts a brand, he/she develops positive beliefs of benevolence, credibility and integrity that are likely to strengthen the bond with the brand. Although not many, due to it being an emergent research theme, there are some papers proving the link between trust and attachment (Lacoeuilhe and Belaïd, 2007; Louis and Lombart, 2010). Thus, a link between brand trust and brand attachment is hypothesized, which means brand trust could have direct and indirect effects on loyalty. Hence:

H6: The greater the retail brand trust the greater the retail brand attachment to the multichannel retailer.

\subsection{Culture as a moderator in the brand-loyalty relationships}

The brand extension literature holds that behaviours based on congruence perceptions differ across cultures. In this research theme, Badrinayaranan et al. (2012) found cross cultural differences in the transfer of retail trust to attitudes and purchase intentions in online stores of multichannel retailers. Referring to the established cultural framework of Hofstede (1980), two cultural dimensions seem to be particularly relevant in our context: individualism-collectivism and uncertainty avoidance. Collectivist versus individualist societies rely more on social approval and less on independent 
decisions. Uncertainty avoidance refers to the extent people feel uncomfortable in novel, unknown, surprising or unusual situations. According to the Hofstede Center ${ }^{1}$, the United Kingdom has an individualism score higher than Spain (i.e. 89 versus 51), and lower uncertainty avoidance (i.e. 35 versus 86). These two dimensions have proved to be influential in online shopping behaviour (Kim et al., 2013), in trust building (Jarvenpaa et al., 1999; Sahi et al., 2016), and in the development of brand loyalty (Lam, 2007). The adoption of online shopping tends to be higher in individualist, lower uncertainty avoidance countries (Tong, 2010; Kim et al., 2013). Individualism-collectivism is related to trust in that members of individualist cultures form trust via a calculative process, whereas collectivist cultures build trust via a prediction or transference process (Lim et al., 2004; Doney et al., 1998). Considering the role of brand as signals, the prevailing view holds that in highly collectivist societies the positive impact of brand credibility enhances belongingness to the group (Erdem et al., 2006). Uncertainty avoidance has also been related to brand trust in that members of a culture ranking high in uncertainty avoidance tend to seek stability, predictability and low risk, thus favouring credible brands as this reduces the perceived risks of shopping (Jarvenpaa et al., 1999; Robinson, 1996). Although members of an uncertainty avoidance culture, such as Spain, may be reluctant to assume the risks of online shopping, as Kim et al. (2013) suggest, the effect of uncertainty avoidance can be mitigated when there is trust between the parties. In this vein, it is expected that collectivism and uncertainty avoidance amplify the brand credibility effects, so that collectivist consumers prefer credible brands because they reinforce their belongingness to the group (Erdem et al., 2006). Thus it may be hypothesized that the link between retail brand trust and offline and online loyalty will be stronger in a collectivist, uncertainty avoidance culture, such as Spain:

H7a: The relationship between retail brand trust and offline loyalty is stronger for Spanish than for

\section{British consumers.}

H7b: The relationship between retail brand trust and online loyalty is stronger for Spanish than for

\section{British consumers.}

Consumers use brands as a way to express attitudes, individualism, and needs. Consumers may use brands to implement two distinct consumption strategies (Godey et al., 2012). First, brands are the

\footnotetext{
${ }^{1}$ https://geert-hofstede.com/countries.html [Accessed 30 March 2016]
} 
visible symbols of consumer tastes (i.e., social salience); second, certain brands represent certain social groups and help consumers to strengthen their membership of these groups (i.e., social identification). While the former may be linked to individualist cultures, the latter can be related to collectivist cultures. Moreover, individualist cultures tend to conformity behaviours (Erdem et al., 2006; Kim et al., 2013). The increased proneness to calculate the consequences of one's behaviour in individualist cultures challenges the emotional bonds with brands. Uncertainty avoidance is linked to the relationship between brand attachment and loyalty in that the brand's potential to elicit a positive emotional response from the average consumer as a result of its use can serve as a means to reduce risk (Matzler et al., 2008). Due to the risk reducing effect of brands, one can expect that in cultures scoring high in uncertainty avoidance, the link between brand attachment and loyalty will be stronger than in low uncertainty avoidance cultures.

H8a: The relationship between retail brand attachment and offline loyalty is stronger for Spanish than for British consumers.

H8b: The relationship between retail brand attachment and online loyalty is stronger for Spanish than for British consumers.

\subsection{Control variables}

To provide a more robust test of the proposed framework, the influence of variables related to shopping motivations and the perception of the Internet is controlled.

The literature on multichannel shopping behaviour has noted that motivations towards shopping influence channel choice (Doherty and Ellis-Chadwick, 2010). Hedonic orientation has often been used to explain channel use; most of the studies claim that hedonic-oriented shoppers will tend to shop offline as the store provides increased sensory and social stimuli (Jones et al., 2006; To et al., 2007). Likewise, consumer involvement with the product category is a relevant variable related to multichannel behaviour as it is strong motivation to spend more time shopping both online and offline (Balabanis and Reynolds, 2001; Jones and Kim, 2010).

On the other hand, TAM variables have been frequently used to explain online shopping. The variables of ease-of-use and usefulness, originally proposed by Davis (1989), were included in our 
model. Perceived ease-of-use of the online channel refers to the degree to which the consumer believes using the Internet for shopping will require little effort (Rose et al., 2012). Perceived usefulness is defined as the belief that the online channel improves the efficiency of the shopping process (e.g.; Ha and Stoel, 2009).

\section{Methodology}

The research model is tested in the context of vertically integrated apparel retailers that have added the online channel to their existing offline retail network, becoming multichannel retailers, and that sell their products under a brand name that is shared with the retail store name. This is a way to avoid possible confusion between retail store brand and product brands if they were different.

\subsection{Data source}

An online survey aimed at British and Spanish multichannel retail customers is the instrument used for data collection. The survey items were originally written in English and then translated into Spanish; the Spanish version of the questionnaire was back-translated to guarantee the semantic equivalence of both versions of the survey. Next, a pre-test was conducted to check if all the items were duly understood and the survey was respondent-friendly. The survey was administered to two Internet panels, one in the UK and another in Spain. These two countries differ significantly in the overall penetration of B2C e-commerce: $82 \%$ of Internet users in the UK had purchased online in 2012, while in Spain this figure was $43 \%$ (Eurostat, 2014). For the purpose of this study, multichannel shoppers are defined as those using both the online and offline channels of a retailer during the shopping process, that is, a consumer who searches online and purchases offline would be a multichannel shopper. Panellists were screened to select those members that fit our definition of multichannel shopper, setting the criteria that they had shopped online during the last year. A non-probabilistic quota-based sampling procedure is used. Gender and age quotas were set for the sample to be representative of multichannel shoppers in the apparel category and country according to the sociodemographic profile of online shoppers presented in "PwC Global Online Shopping Habits" (PwC, 
2014). Data were collected in November 2013 and comprises 761 shoppers, allowing the ratio of respondents to parameters to be maintained above 5:1, as recommended by Bentler (1989).

Since the present study aims at testing the moderating role of culture in the relations between brand trust and attachment and loyalty, two balanced samples are obtained, being $49.9 \%$ of respondents from Spain and $50.1 \%$ from United Kingdom. Regarding gender, $33.4 \%$ of respondents are male and $66.6 \%$ female for the total sample, aiming to reflect the customer base of apparel retailers. Similarly, all age groups are represented in the sample (i.e. $18.7 \%$ is $18-24$ years old, $30.7 \%$ is $25-34,25.4 \%$ is $35-44$, $16.7 \%$ is $45-54$ and $8.5 \%$ is older than 54$)$. Concerning respondents' occupation, employees $(60.9 \%)$, business owners $(8.1 \%)$, students $(10.9 \%)$, unemployed $(9.2 \%)$, housewives $(8.2 \%)$ and pensioners (2.7\%) participated in the survey.

\subsection{Measurement and operationalization}

The questionnaire asked the respondent to identify from an extensive list, the retailer where he/she shopped more often online and purchased frequently either online or offline. Then, most of questions had to be answered thinking about that specific retailer. All the retailers considered were originally offline retailers that have become multichannel retailers by adding the online sales channel. In order to guarantee that respondents were multichannel customers, those that stated not having visited the physical store of the retailer in the last year were filtered.

The focus variables for this paper are variables to measure customer relationship with the brand and variables to capture customer loyalty to the online and offline channels. These constructs were measured through multi-item scales employed in previous studies and measured on five-point Likert scales. Brand trust was measured with the four-item scale of Chaudhuri and Holbrook (2001), and brand attachment used the four-item scale developed by Park et al. (2010). Online and offline loyalty were measured with four-item scales adapted from Yang and Peterson (2004), which capture the attitudinal and behavioural components of the construct. Finally, the control variables were measured using scales previously tested in the literature: ease-of-use and usefulness (Davis, 1989), hedonic orientation (Konuş et al., 2008), and product involvement (Kressmann et al., 2006). Face validity of 
all these scales was tested by showing the adapted items to a panel of experts and a small group of multichannel shoppers and analyzing their responses qualitatively (Gaur and Gaur, 2009). Final wording of the items related to each of the latent variables is shown in the second column of Table 1 . Data were standardized to avoid problems inherent to non-normality, and Q-Q plots and asymmetry and kurtosis tests were performed (Hair et al., 2003), resulting in no evidence of lack of compliance to normality conditions.

\subsection{Statistical analysis method}

In order to confirm the validity of the proposed model in Figure 1, an analysis of covariances for estimating a structural equation model (SEM) was performed. This allowed simultaneously testing the causal relationships between exogenous constructs and endogenous constructs (Anderson and Gerbing, 1988) so that the full nomology of the hypothesized research model was assessed. A two-step procedure was followed. First, the quality of the measurement of the constructs was analyzed through a confirmatory factor analysis, and second, a structural or causal model was estimated (Hoyle, 2012). In order to analyze the influence of culture as a moderator a multigroup structural equations model was estimated (Kaplan, 2008) considering two groups differing in terms of consumer nationality, i.e. Spanish and British multichannel shoppers.

\section{Discussion of results}

The results of the confirmatory factor analysis are shown in Table 1. Adjustment indexes are over 0.9, thus indicating a good fit of the model, and the mean square error is low. The reliability of the scales can be confirmed, since both composite reliabilities and Cronbach's alpha coefficients are above the recommended value of 0.7 for all constructs, the variances extracted are above 0.5 and the standardized factor loadings are statistically significant for all items. This allows us to confirm the convergent validity of the proposed model.

Table 1. Confirmatory factor analysis results

\begin{tabular}{|l|c|c|c|c|c|c|}
\hline Construct & Item & $\begin{array}{c}\text { St. loading } \\
\text { factor } \\
\text { (st. error) }\end{array}$ & $\mathbf{t}$ & $\begin{array}{c}\text { Cronbach's } \\
\text { alpha }\end{array}$ & $\begin{array}{c}\text { Composite } \\
\text { reliability }\end{array}$ & $\begin{array}{c}\text { Average } \\
\text { variance } \\
\text { extracted }\end{array}$ \\
\hline Brand trust & BT1 & 0.772 & - & 0.877 & 0.880 & 0.649 \\
\hline
\end{tabular}




\begin{tabular}{|c|c|c|c|c|c|c|}
\hline & $\begin{array}{l}\text { BT2 } \\
\text { BT3 } \\
\text { BT4 }\end{array}$ & $\begin{array}{l}0.709(0.055) \\
0.881(0.055) \\
0.850(0.052)\end{array}$ & $\begin{array}{l}17.789^{*} \\
21.846^{*} \\
21.847^{*}\end{array}$ & & & \\
\hline Brand attachment & $\begin{array}{l}\text { BA1 } \\
\text { BA2 } \\
\text { BA3 } \\
\text { BA4 }\end{array}$ & $\begin{array}{c}0.787 \\
0.801(0.034) \\
0.809(0.048) \\
0.851(0.046)\end{array}$ & \begin{tabular}{|c|}
- \\
$30.080^{*}$ \\
$22.992^{*}$ \\
$26.117^{*}$
\end{tabular} & 0.885 & 0.886 & 0.660 \\
\hline Offline loyalty & $\begin{array}{l}\text { OffL1 } \\
\text { OffL2 } \\
\text { OffL3 } \\
\text { OffL4 }\end{array}$ & $\begin{array}{c}0.902 \\
0.891(0.026) \\
0.886(0.026) \\
0.713(0.041) \\
\end{array}$ & \begin{tabular}{|c|}
- \\
$36.458^{*}$ \\
$38.347^{*}$ \\
$20.835^{*}$
\end{tabular} & 0.908 & 0.913 & 0.725 \\
\hline Online loyalty & $\begin{array}{l}\text { OnL1 } \\
\text { OnL2 } \\
\text { OnL3 } \\
\text { OnL4 }\end{array}$ & $\begin{array}{c}0.890 \\
0.852(0.031) \\
0.864(0.038) \\
0.739(0.040)\end{array}$ & \begin{tabular}{|c|}
- \\
$31.030^{*}$ \\
$28.022^{*}$ \\
$22.207 *$ \\
\end{tabular} & 0.900 & 0.904 & 0.703 \\
\hline Usefulness & $\begin{array}{l}\text { U1 } \\
\text { U3 } \\
\text { U4 }\end{array}$ & $\begin{array}{c}0.634 \\
0.799(0.076) \\
0.877(0.083) \\
\end{array}$ & \begin{tabular}{|c|}
- \\
$14.646^{*}$ \\
$15.383^{*}$
\end{tabular} & 0.802 & 0.818 & 0.603 \\
\hline Ease of use & $\begin{array}{l}\text { EU2 } \\
\text { EU3 }\end{array}$ & $\begin{array}{c}0.801 \\
0.817(0.062)\end{array}$ & $\begin{array}{c}- \\
15.900^{*}\end{array}$ & 0.791 & 0.791 & 0.655 \\
\hline Hedonic orientation & $\begin{array}{l}\mathrm{HO} 1 \\
\mathrm{HO} 2\end{array}$ & $\begin{array}{c}0.870 \\
0.692(0.053)\end{array}$ & \begin{tabular}{|c|}
- \\
$13.929 *$ \\
\end{tabular} & 0.752 & 0.761 & 0.618 \\
\hline Product involvement & $\begin{array}{l}\text { PI1 } \\
\text { PI2 } \\
\text { PI3 } \\
\text { PI4 }\end{array}$ & $\begin{array}{c}0.821 \\
0.861(0.037) \\
0.791(0.042) \\
0.865(0.038)\end{array}$ & \begin{tabular}{|c|}
- \\
$27.422 *$ \\
$24.679 *$ \\
$27.797 *$ \\
\end{tabular} & 0.901 & 0.902 & 0.697 \\
\hline
\end{tabular}

Satorra-Bentler Chi-square: 846.64; Degrees of freedom: 296; CFI: 0.949; IFI: 0.949; Bentler-Bonett NNFI: 0.939; RMSEA: 0.050 * Significant: $\mathrm{p}<0.05$

In order to check the discriminant validity, the correlations between all pairs of constructs are calculated as described by Fornell and Larcker (1981). This test states that the discriminant validity is confirmed provided that the variance extracted estimates are greater than the squared correlation estimate for any two constructs. Being appointed as the best method (Farrell, 2010), this technique allows us to confirm the discriminant validity of the constructs included in our model (Table 2).

Table 2. Means, standard deviations and square root of AVE and correlations between constructs

\begin{tabular}{|c|c|c|c|c|c|c|c|c|c|c|}
\hline \multirow{2}{*}{ Construct } & \multirow{2}{*}{ Mean } & \multirow{2}{*}{$\begin{array}{c}\text { St. } \\
\text { dev. }\end{array}$} & \multicolumn{8}{|c|}{ Correlations } \\
\hline & & & BT & $\mathrm{BA}$ & $\mathrm{HO}$ & PI & OffL & $\mathrm{U}$ & $\mathrm{EU}$ & OnL \\
\hline Brand trust & 3.927 & 0.811 & 0.806 & 0.743 & 0.395 & 0.245 & 0.659 & 0.486 & 0.451 & 0.658 \\
\hline Brand attachment & 3.380 & 1.026 & & 0.812 & 0.378 & 0.438 & 0.584 & 0.309 & 0.264 & 0.605 \\
\hline Hedonic orientation & 3.730 & 0.937 & & & 0.786 & 0.559 & 0.425 & 0.312 & 0.375 & 0.386 \\
\hline Product involvement & 2.978 & 0.957 & & & & 0.834 & 0.313 & 0.172 & 0.190 & 0.372 \\
\hline Offline loyalty & 3.983 & 0.801 & & & & & 0.851 & 0.344 & 0.322 & 0.791 \\
\hline Usefulness & 3.943 & 0.885 & & & & & & 0.777 & 0.750 & 0.475 \\
\hline Ease of use & 4.001 & 0.857 & & & & & & & 0.809 & 0.421 \\
\hline Online loyalty & 3.906 & 0.825 & & & & & & & & 0.838 \\
\hline
\end{tabular}

Diagonal values in bold are square roots of AVE and others (off-diagonal) are correlations between variables

Next, the structural model was tested. The sample was divided in two subsamples: one of Spanish consumers and another one of British consumers to perform a multigroup analysis (Table 3). This allowed investigation of the existence of cultural differences. Again, the adjustment rates show a good fit of the model, so that the parameters may be interpreted. 
Table 3. Results of multigroup analysis

\begin{tabular}{|l|c|c|c|}
\hline \multicolumn{1}{|c|}{ Standardized coefficients } & $\begin{array}{c}\text { Spain } \\
\mathbf{( N = 3 8 0 )}\end{array}$ & $\begin{array}{c}\text { UK } \\
\mathbf{( N = 3 8 1 )}\end{array}$ & Hypotheses \\
\hline Offline loyalty $\rightarrow$ Online loyalty & $0.571^{*}$ & $0.673^{*}$ & H1 supported \\
\hline Brand trust $\rightarrow$ Offline loyalty & $0.445^{*}$ & $0.548^{*}$ & H2 supported \\
\hline Brand trust $\rightarrow$ Online loyalty & $0.136^{*}$ & $0.149^{*}$ & H3 supported \\
\hline Brand attachment $\rightarrow$ Offline loyalty & $0.165^{*}$ & $0.172^{*}$ & H4 supported \\
\hline Brand attachment $\rightarrow$ Online loyalty & 0.082 & 0.076 & H5 not supported \\
\hline Brand trust $\rightarrow$ Brand attachment & $0.764^{*}$ & $0.704^{*}$ & H6 supported \\
\hline Control variables & & & Effect for Spain and UK \\
\hline Hedonic orientation $\rightarrow$ Offline loyalty & $0.168^{*}$ & $0.146^{*}$ & No effect \\
\hline Hedonic orientation $\rightarrow$ Online loyalty & -0.073 & -0.024 & No effect \\
\hline Product involvement $\rightarrow$ Offline loyalty & 0.089 & 0.040 & Effect only for UK \\
\hline Product involvement $\rightarrow$ Online loyalty & $0.170^{*}$ & $0.086^{*}$ & Effect only for Spain \\
\hline Ease of use $\rightarrow$ Online loyalty & 0.079 & $0.081^{*}$ & H7a not supported \\
\hline Usefulness $\rightarrow$ Online loyalty & $0.217^{*}$ & 0.059 & H7b not supported \\
\hline Moderating effect of culture & $\mathbf{C h \mathbf { i } ^ { 2 }}$ & $\mathbf{p - v a l u e}$ & H8a not supported \\
\hline Brand trust $\rightarrow$ Offline loyalty & 0.922 & 0.337 & H8b not supported \\
\hline Brand trust $\rightarrow$ Online loyalty & 0.217 & 0.641 & \\
\hline Brand attachment $\rightarrow$ Offline loyalty & 0.471 & 0.492 & \\
\hline Brand attachment $\rightarrow$ Online loyalty & 0.648 & 0.421 & \\
\hline Adjustment measures & &
\end{tabular}

The value and significance of the parameters allow us to test the hypotheses. As a result, it should be noted, first, that the strongest predictor of online loyalty is offline loyalty, both in Spain and the UK, in the line of Hypothesis 1. This confirms the relevant interaction effects between offline and online behaviours and the importance of cross-channel shopping.

Second, all relationships related to brand trust have the signs that had been hypothesized from the literature review. Brand trust influences positively and significantly offline loyalty (Hypothesis 2) both for British and Spanish apparel retail customers. Brand trust also affects positively online loyalty (Hypothesis 3) and brand attachment (Hypothesis 6). The influence of brand attachment on offline loyalty is confirmed, supporting Hypothesis 4. Consumers that feel more connected to the retail brand are more likely to repatronize the offline stores. By contrast, the relationship brand attachment-online loyalty (Hypothesis 5) is not significant either for the Spanish consumers or the British ones. This result may be explained as attachment having been traditionally related to social bonding, personal ties or linkages forged during interaction, personal friendship and liking shared by a buyer and seller, as well as links of personal selves or identities through self-disclosure; closeness; support or advice; empathy and responsiveness, feelings of affiliation, or connectedness; and shared experiences (Liang and Wang, 2008). In this sense, attachment may have been developed through personal or face-to-face 
service encounters in the early stage of the relationship with the retailer, before the existence of the online store, so that there is no direct influence of brand attachment on online loyalty but mediated through offline loyalty.

Lastly, the moderating role of culture on the relationship between brand trust and attachment, and both offline and online loyalty (Hypotheses 7 and 8) is not significant. In particular, although the coefficients for the relation brand trust $\rightarrow$ offline loyalty $\left(\gamma_{2}=0.445\right.$ for Spain and $\gamma_{2}=0.548$ for UK; $\mathrm{p}<0.05)$ and brand trust $\rightarrow$ online loyalty $\left(\gamma_{2}=0.136\right.$ for Spain and $\gamma_{2}=0.149$ for UK; $\left.p<0.05\right)$ appear to be quite different in the two countries studied, their differences are not statistically significant.

These findings may be explained by the interaction of different effects. First, higher uncertainty avoidance would mean that Spanish consumers favour credible brands, and the collectivist culture amplifies the brand credibility effects, but the higher individualism of British consumers could make them more likely to trust a firm and shop online. Similarly, for brand attachment, differences between cultures regarding social salience and social identification do not seem to influence the link between brand attachment and loyalty. Overall, these results show that although the parameters from brand trust and attachment to loyalty are slightly different between the UK and Spain, the general framework of brand trust and brand attachment effects is robust across the countries studied. This may be related to the similarity in the way UK and Spanish consumers respond to consumer-based brand equity scales, as reported by Buil et al. (2008). It thus might be inferred that in spite of cultural differences, consumers from Spain and UK present important similarities in terms of brand-related variables. Moreover, similarities in the results obtained for Spanish and British consumers may be explained because of the post-financial crisis period in which data are collected; in this sense, L'Observatoire Cetelem (2010) concludes from research conducted in several Western European countries, including Spain and UK, that the global crisis has encouraged rational consumer behaviour of Europeans and has speeded up changes in spending patterns, being potentially related to consumer responses towards brand variables

The influence of the control variables is not insignificant but is weaker and more context-specific than the central variables of our model. Hedonic orientation exerts a significant positive influence on 
offline loyalty $\left(\gamma_{\mathrm{HO}} \rightarrow\right.$ offL $=0.168$ for Spain and $\gamma_{\mathrm{HO}} \rightarrow$ offL $=0.146$ for $\left.\mathrm{UK} ; \mathrm{p}<0.05\right)$ but not on online loyalty $\left(\gamma_{\mathrm{HO} \rightarrow \mathrm{OnL}}=-0.073\right.$ for Spain and $\gamma_{\mathrm{HO} \rightarrow \mathrm{OnL}}=-0.024$ for UK; ns). In contrast, product involvement is positively related to online loyalty $\left(\gamma_{\mathrm{PI} \rightarrow \mathrm{OnL}}=-0.170\right.$ for Spain and $\gamma_{\mathrm{PI} \rightarrow \mathrm{OnL}}=-0.086$ for $\left.\mathrm{UK} ; \mathrm{p}<0.05\right)$, whereas no significant influence is obtained for offline loyalty in any of both cultures $\left(\gamma_{\mathrm{PI}} \rightarrow\right.$ OffL $=-0.089$ for Spain and $\gamma_{\mathrm{PI} \rightarrow \mathrm{OffL}}=-0.040$ for UK; ns).

Concerning TAM variables, the influence of perceived ease-of-use on customer loyalty towards the online channel is significant for British consumers $\left(\gamma_{\mathrm{EU}} \rightarrow \mathrm{OnL}=0.081 ; \mathrm{p}<0.05\right)$, but not for Spanish multichannel shoppers $\left(\gamma_{\mathrm{EU}} \rightarrow \mathrm{OnL}=0.079 ; \mathrm{ns}\right)$. The two values are quite similar and possibly the difference of significance is only apparent, i.e. it may be that both are near to the threshold value and only UK is lower than $5 \%$. Finally, the influence of perceived usefulness on online loyalty is significant for Spanish consumers $\left(\gamma_{U} \rightarrow \mathrm{OnL}=0.217 ; \mathrm{p}<0.05\right)$, but not for their British fellows $\left(\gamma_{U} \rightarrow\right.$ $\mathrm{OnL}=0.059 ; \mathrm{ns})$. This finding may be explained by the fact that e-commerce is not so consolidated in Spain as in UK, so that usefulness of the online channel strongly influences customer loyalty towards the online store in the case of Spanish shoppers, while British consumers are widely used to this channel and perceived usefulness does not exert a significant effect on online loyalty anymore.

\section{Conclusions and implications}

\subsection{Theoretical contribution}

Our study makes an incremental contribution to the limited literature on the interaction effects between offline and online channels, which is based on the cognitive dissonance theory. Our results reveal that offline beliefs, attitudes and behaviours make a strong impact on online loyalty. This shows the validity of applying the theory of cognitive dissonance to explain multichannel shopping behaviours (Jones and Kim, 2010; Fernández-Sabiote and Román, 2013). In order to keep congruent beliefs, shoppers transfer their existing beliefs and behavioural patterns from the offline context to the online channel.

Our investigation analysed the interaction between online and offline channels focusing on the customer brand relationship and contributes to advance our knowledge of this topic in the following 
ways. First, our main conclusion is that offline loyalty is the strongest determinant of online loyalty. This is in accordance to previous research that showed that attitude towards the offline channel transferred to the online channel (Kim and Park, 2005) or offline patronage affected online shopping intentions (Jones and Kim, 2010). No previous study proved, however, the presence of the relationship between the constructs of offline and online loyalty. Secondly, our results show that the retailer brand plays a relevant role in driving shopping intentions towards both the offline and the online channel of the retailer. Brand trust is a powerful variable explaining offline and online channel loyalty in line with previous results (Sirdeshmukh et al., 2002; Jones and Kim, 2010). Brand attachment contributes to explain offline loyalty as Huang et al. (2014) obtained, but not loyalty towards the online shop, suggesting that brand attachment builds through interactions in physical stores and then transfers to online loyalty. This is a novel finding since the link between brand attachment and loyalty in the multichannel environment had not been tested previously. In the presence of these brand-related variables, other variables that could have an effect on multichannel retailer loyalty, taken as controls, are of little relevance. Our two main contributions thus confirm that multichannel retailers can benefit from synergies between their offline store network and the online channel. This extends the literature that suggested channel synergies, such as the positive effects of offline trust on online trust (Kuan and Bock, 2007), of offline trust on online shopping intentions (Hahn and Kim, 2009; Jones and Kim, 2010), and of offline brand attitude on online purchase intention (Kwon and Lennon (2009a), by adding the construct of brand attachment and by focusing on the key relationship between offline and online loyalty. Thirdly, our results show that cultural differences do not affect the relationships investigated, as we initially hypothesized. Fashion retail brands are basically brands with a global appeal, and the customer relationship with the brand appears to have globalized in the same way. While variables related to technology may affect consumers differently from different countries, the key determinants of loyalty in our model (i.e. brand trust and brand attachment) have a similarly strong effect. This supports the robustness of our research model.

\subsection{Managerial contribution}

One of the most important issues that multichannel retailers face is how to manage offline and online channels to obtain synergies that improve overall performance. Our study is focused on the apparel 
sector, which is leading growth in online sales and brand values. Multichannel retailers should coordinate their online and offline channels to build stronger brands through an enhanced multichannel shopping experience. In the current multichannel environment, consumers have a plethora of choices and as they cross the channels during the shopping process, they may not only switch channels but also switch retailers. In this context, loyalty becomes more of a challenge. Multichannel retailers are in a privileged position when compared to pure online players to build customer-brand relationships that encourage loyalty both offline and online. It is evident that today there is not anymore a clear divide between online and offline shoppers; online and offline customers are not different people and those customers more likely to develop online loyalty are those that are loyal to the offline stores. Retailers can increase online loyalty by enhancing trust beliefs and stimulating loyalty towards their offline channel, exploiting the synergies between the offline store network and the online channel. Even if some retailers have considered e-commerce as a low-cost way of internationalization, it is worth considering that brand attachment contributes to generate offline loyalty but not online loyalty, being thus still relevant for international retailers to adopt a multichannel approach in their internationalization strategies.

Therefore, if multichannel retailers want to build customer loyalty, they should make every effort to build trust and attachment towards the brand. The efforts to build stronger bonds between the customer and the retail brand translate into higher loyalty, particularly towards the offline channels. Thus, retailers can leverage their offline presence, by providing fulfilling offline experiences through store design, atmosphere, and customer service; and they can also build the brand online by promoting a sense of community through social media.

\subsection{Limitations and future research directions}

Our paper has certain limitations stemming from the research design. Although using online panels is effective to reach multichannel shoppers, it might introduce some bias on the results because of different motivations of this population. In addition to this, further research should adopt a probabilistic sampling approach instead of the non-probabilistic quota-based sampling procedure adopted in this research. Furthermore, the validity of these findings should be tested for other cultural 
variables different from nationality, e.g. Hofstede's cultural dimensions. Moreover, consumer-reported measures of behaviour have been considered. It would be beneficial to use actual channel choice for specific shopping occasions. As well, future research could track consumers across several purchase episodes, by collecting longitudinal data showing consumers' choice of channel given the choice taken in the previous purchase episode. Also, taking into account the situational factors affecting consumers' channel behaviour is necessary to further our understanding of multichannel behaviour as consumers could purchase in one channel on one occasion and use a different channel on another occasion. Future research could also pay attention to the online retailers that are moving offline by opening brick-andmortar stores or collection points and analyse if the customer-brand relationships suggested in this study hold in this newly built multichannel context. Additionally, exploring the influence of retailerspecific variables may help to refine our theoretical framework. Retailer actions such as channel integration measures and social media strategies are likely to influence brand beliefs and behavioural responses. Finally, further research may consider that multichannel familiarity or preferences are possibly related to personal attitude (e.g., education, web-network-global thinking, etc.) rather than to average/national cultural factors, making these factors potential moderators in the relationship between brand-related variables and offline and online loyalty towards the retailer.

\section{References}

Anderson, J. C. and Gerbing, D. W. (1988), "Structural equation modeling in practice: A review and recommended two-step approach", Psychological Bulletin, Vol. 103 No. 3, pp. 123-133.

Badrinarayanan, V., Becerra, E.P., Kim, C.H. and Madhavaram, S. (2012), "Transference and congruence effects on purchase intentions in online stores of multi-channel retailers: initial evidence from the US and South Korea", Journal of the Academy of Marketing Science, Vol. 40 No. 4, pp. 539-557.

Balabanis, G. and Reynolds N.L. (2001), "Consumer attitudes towards multi-channel retailers' Web sites: The role of involvement, brand attitude, Internet knowledge and visit duration", Journal of Business Strategies, Vol. 18 No. 2, pp. 105-131.

Bentler, P.M. (1989), EQS, Structural Equations, Program Manual, Program Version 3.0. BMDP Statistical Software, Inc., Los Angeles.

Bock, G.W., Lee, J., Kuan, H.H. and Kim, J.H. (2012), "The progression of online trust in the multichannel retailer context and the role of product uncertainty", Decision Support Systems, Vol. 53 No. 1, pp. 97-107.

Bowlby, J. (1979), The making and breaking of affectional bonds. Tavistock, London.

Buil, I., de Chernatony, L., and Martinez, E. (2008), "A cross-national validation of the consumerbased brand equity scale". Journal of Product \& Brand Management, Vol. 17 No. 6, pp. 384-392.

Burt, S., and Davies, K. (2010), "From the retail brand to the retailer as a brand: themes an issues in retail branding research." International Journal of Retail and Distribution Management, Vol. 38 No. $11 / 12$, pp. $865-878$. 
Chaudhuri, A. and Holbrook, M.B. (2001), "The chain of effects from brand trust and brand affect to brand performance: the role of brand loyalty", Journal of Marketing, Vol. 65 No. 2, pp. 81-93.

Danaher, P.J., Wilson, I.W. and Davis, R.A. (2003), "A comparison of online and offline consumer brand loyalty", Marketing Science, Vol. 22 No. 4, pp. 461-476.

Das, G. (2014a). "Impacts of retail brand personality and self-congruity on store loyalty: the moderating role of gender", Journal of Retailing and Consumer Services, Vol. 21 No. 2, pp. 130138.

Das, G. (2014b). "Linkages of retailer personality, perceived quality and purchase intention with retailer loyalty: A study of Indian non-food retailing". Journal of Retailing and Consumer Services, Vol. 21 No. 3, pp. 407-414.

Das, G. (2015). "Impact of store attributes on consumer-based retailer equity: An exploratory study of department retail stores", Journal of Fashion Marketing and Management, Vol. 19 No. 2, pp. 188204.

Das, G. (2016), "Antecedents and consequences of trust: an e-tail branding perspective", International Journal of Retail \& Distribution Management, Vol. 44 No. 7, pp. 713-730.

Davis, F.D. (1989), "Perceived usefulness, perceived ease-of-use, and user acceptance of information technology", MIS Quarterly, Vol. 13, pp. 319-339.

Dick, A.S. and Basu, K. (1994), "Customer loyalty: toward an integrated conceptual framework", Journal of the Academy of Marketing Science, Vol. 22 No. 2, pp. 99-113.

Doherty, N. F. and Ellis-Chadwick, F. (2010), "Internet retailing: the past, the present and the future", International Journal of Retail \& Distribution Management, Vol. 38, No. 11/12, pp. 943965.

Dolbec, P.Y. and Chebat, J.C. (2013), "The impact of a flagship vs. a brand store on brand attitude, brand attachment and brand equity", Journal of Retailing, Vol. 89 No. 4, pp. 460-466.

Doney, P.M., Cannon, J.P. and Mullen, M.R. (1998), "Understanding the influence of national culture on the development of trust", Academy of Management Review, Vol. 23, pp. 601-620.

Erdem, T., Swait, J. and Valenzuela, A. (2006), "Brands as Signals: A Cross-Country Validation Study", Journal of Marketing, Vol. 70 (January), pp. 34-49.

Euromonitor International (2014), "Internet vs store-based shopping: the global move towards omnichannel retailing", available at: http://www.euromonitor.com/internet-vs-store-basedshopping-the-global-move-towards-omnichannel-retailing/report (accessed 23 March 2016).

Eurostat (2014), "Eurostat Yearbook", available at: http://epp.eurostat.ec.europa.eu/statistics explained/index.php/Europe in figures Eurostat yearbook. (accessed 23 March 2016).

Farag, S., Schwanen, T., Dijst, M. and Faber, J. (2007), "Shopping online and/or in-store? A structural equation model of the relationships between e-shopping and in-store shopping", Transportation Research Part A: Policy and Practice, Vol. 41 No.2, pp. 125-141.

Farrell, A.M. (2010), "Insufficient discriminant validity: a comment on Bove, Pervan, Beatty and Shiu (2009)", Journal of Business Research, Vol. 63 No. 3, pp. 324-327.

Fernández-Sabiote, E. and Román, S. (2012), "Adding clicks to bricks: A study of the consequences on customer loyalty in a service context", Electronic Commerce Research and Applications, Vol. 11 No. 1, pp. 36-48.

Festinger, L. (1957), A Theory of Cognitive Dissonance. Row Peterson, Evanston, IL.

Fornari, E., Fornari, D., Grandi, S., Menegatti, M., and Hofacker, C. F. (2016), "Adding store to web: migration and synergy effects in multi-channel retailing", International Journal of Retail \& Distribution Management, Vol. 44, No. 6, pp. 658-674.

Fornell, C. and Larcker, D.F. (1981), "Evaluating structural equation models with unobservable variables and measurement error", Journal of Marketing Research, Vol. XVIII (February), pp. 3950.

Gaur, A.S., and Gaur, S.S. (2009), Statistical Methods for Practice and Research: A Guide to Data Analysis using SPSS ( $2^{\text {nd }}$ ed.), Sage, London.

Gefen, D., Karahanna, E. and Straub, D.W. (2003), "Trust and TAM in online shopping: an integrated model". MIS Quarterly, Vol. 27 No. 1, pp. 51-90. 
Godey, B., Pederzoli, D., Aiello, G., Donvito, R., Chan, P., Oh, H., Singh, R., Skorobogatykh, I., Tsuchiya, J. and Weitz, B. (2012), "Brand and country-of-origin effect on consumers' decision to purchase luxury products", Journal of Business Research, Vol. 65 No. 10, pp. 1461-1470.

Guenzi, P., Johnson, M.D. and Castaldo, S. (2009), "A comprehensive model of customer trust in two retail stores", Journal of Service Management, Vol. 20 No. 3, pp. 290-316.

Ha, J. and Stoel, L. (2009), "Consumer E-Shopping Acceptance: Antecedents in a Technology Acceptance Model”, Journal of Business Research, Vol. 62 No. 5, pp. 565-571.

Hahn, K.H. and Kim, J. (2009), "The effect of offline brand trust and perceived internet confidence on online shopping intention in the integrated multi-channel context", International Journal of Retail and Distribution Management, Vol. 37 No. 2, pp. 126-141.

Hair, J.E., Black. W.C., Babin, B.J., Anderson, R.E., Tatham, R.L. (2003), Multivariate data analysis, 6th ed. Pearson Prentice Hall, Upper Saddle River, NJ

Herhausen, D., Binder, J., Schögel, M. and Herrmann, A. (2015), "Integrating Bricks with Clicks: Retailer-Level and Channel-Level Outcomes of Online-Offline Channel Integration", Journal of Retailing, Vol. 91 No. 2, pp. 309-325.

Hofstede, G. (1980). Culture's consequences: International differences in work-related values. Sage Publications, Beverly Hills, California.

Hoyle, R.H. (ed) (2012), Handbook of Structural Equations Modeling. Guilford, New York NY.

Hsieh, Y. C., Roan, J., Pant, A., Hsieh, J. K., Chen, W. Y., Lee, M., \& Chiu, H. C. (2012), "All for one but does one strategy work for all? Building consumer loyalty in multi-channel distribution", Managing Service Quality: An International Journal, Vol. 22 No. 3, 310-335.

Huang, C., Fang, S., Huang, S., Chang, S. and Fang, S. (2014), "The impact of relational bonds on brand loyalty: the mediating effect of brand relationship quality", Managing Service Quality: An International Journal Vol. 24 No. 2, pp. 184-204.

Jarvenpaa, S.L., Tractinsky, N. and Saarinen, L. (1999), "Consumer trust in an internet store: a cross cultural validation", Journal of Computer Mediated Communication, Vol. 5 No. 2.

Jones, C. and Kim, S. (2010), "Influences of retail brand trust, off-line patronage, clothing involvement and website quality on online apparel shopping intention", International Journal of Consumer Studies, Vol. 34 No. 6, pp. 627-637.

Jones, M.A, Reynolds, K.E. and Arnold, M.J. (2006), "Hedonic and utilitarian shopping value: Investigating differential effects on retail outcomes", Journal of Business Research, Vol. 59 No. 9 , pp. 974-981.

Kaplan, D. (2008), Structural Equation Modeling: Foundations and Extensions (2nd ed.). Sage Publishing, London.

Keller, K.L. (2010), "Brand equity management in a multichannel, multimedia retail environment", Journal of Interactive Marketing, Vol. 24 No. 2, pp. 58-70.

Khan, I., and Rahman, Z. (2016), "E-tail brand experience's influence on e-brand trust and e-brand loyalty: the moderating role of gender", International Journal of Retail \& Distribution Management, Vol. 44, No. 6, pp. 588-606.

Kim, J. and Park, J. (2005), "A consumer shopping channel extension model: attitude shift toward the online store", Journal of Fashion Marketing and Management, Vol. 9 No. 1, pp. 106-121.

Kim, J., Yang, K. and Yong Kim, B. (2013), "Online retailer reputation and consumer response: examining cross cultural differences", International Journal of Retail \& Distribution Management, Vol. 41 No. 9, pp. 688-705.

Konuş, U., Verhoef, P.C. and Neslin, S.A. (2008), "Multichannel shopper segments and their covariates", Journal of Retailing, Vol. 84 No. 4, pp. 398-413.

Kressmann, F., Sirgy, M.J., Herrmann, A. and Huber, F. (2006), "Direct and indirect effects of selfimage congruence on brand loyalty", Journal of Business Research, Vol. 59, pp. 955-964.

Kuan, H.H. and Bock, G.W. (2007), "Trust transference in brick and click retailers: An investigation of the before-online-visit phase". Information and Management, Vol. 44 No. 2, pp. 175-187.

Kushwaha, T. and Shankar, V. (2013), "Are multichannel customers really more valuable? The moderating role of product category characteristics", Journal of Marketing, Vol. 77 No. 4, pp. 6785.

Kwon, W.S. and Lennon, S.J. (2009a), "Reciprocal effects between multichannel retailers' offline and online brand images", Journal of Retailing, Vol. 85 No. 3, pp. 376-390. 
Kwon, W.S. and Lennon, S.J. (2009b), "What induces online loyalty? Online versus offline brand images", Journal of Business Research, Vol. 62 No. 5, pp. 557-564.

L'Observatoire Cetelem (2010), "Consommer en 2010: Pas Moins, Mais Mieux". Available at $\mathrm{http}: / /$ observatoirecetelem.com/wpcontent/uploads/2013/08/observatoire_cetelem_2010_consommer_en_2010.pdf

Lacoeuilhe, J. and Belaïd, S. (2007), "Quelle(s) mesure(s) pour l'attachement a' la marque?", Revue Française du Marketing, Vol. 213, pp. 7-25.

Lam, D. (2007), "Cultural influence on proneness to brand loyal", Journal of International Consumer Marketing, Vol. 19 No. 3, pp. 7-21.

Liang, C.J. and Wang, W.H. (2008), "Do loyal and more involved customers reciprocate retailer's relationship efforts?" Journal of Services Research, Vol. 8 No. 1, 63-90.

Lim, K.H., Leung, K., Sia, C.L. and Lee, M.K. (2004), "Is eCommerce boundary-less? Effects of individualism-collectivism and uncertainty avoidance on Internet shopping", Journal of International Business Studies, Vol. 35 No. 6, pp. 545-559.

Kim, J. and Park, J. (2005), "A consumer shopping channel extension model: attitude shift toward the online store". Journal of Fashion Marketing and Management: An International Journal, Vol. 9 No. 1, pp. 106-121.

Kim, J., Yang, K., and Yong Kim, B. (2013), "Online retailer reputation and consumer response: examining cross cultural differences", International Journal of Retail \& Distribution Management, Vol. 41 No.9, pp. 688-705.

Louis, D. and Lombart, C. (2010), "Impact of brand personality on three major relational consequences (trust, attachment, and commitment to the brand)", Journal of Product and Brand Management, Vol. 19 No. 2, pp. 114-130.

Matzler, K., Grabner-Kräuter, S. and Bidmon, S. (2008), "Risk aversion and brand loyalty: the mediating role of brand trust and brand affect", Journal of Product \& Brand Management, Vol. 17 No. 3, pp. 154-162.

Millward Brown (2014), "BrandZ Top 100 most valuable global brands 2014". Millward Brown.

Neslin, S.A., Grewal, D., Leghorn, R., Shankar, V., Teerling, M.L., Thimas, J.S. and Verhoef, P.C. (2006), "Challenges and opportunities in multichannel customer management", Journal of Service Research, Vol. 9 No. 2, pp. 95-112.

Park, W.C., MacInnis, D.J., Priester, J., Eisingerich, A.B. and Iacobucci, D. (2010), "Brand attachment and brand attitude strength: conceptual and empirical differentiation of two critical brand equity drivers", Journal of Marketing, Vol. 74 No. 6, pp. 1-17.

PwC (2014), "PwC Global Online Shopping Habits", available at: http://www.pwc.com/gx/en/retailconsumer/retail-consumer-publications/global-multi-channel-consumer-survey/index.jhtml (accessed 23 March 2016).

Rafiq, M. and Fulford, H. (2005), "Loyalty transfer from offline to online stores in the UK grocery industry", International Journal of Retail \& Distribution Management, Vol. 33 No. 6, pp. 444-460.

Robinson, C. (1996), "Asian Culture: The Marketing Consequences", Journal of the Market Research Society, Vol. 38 No. 1, pp. 55-63.

Rose, S., Clark, M., Samouel, P. and Hair, N. (2012), "Online customer experience in e-retailing: an empirical model of antecedents and outcomes", Journal of Retailing, Vol. 88 No. 2, pp. 308-322.

Sahi, G. K., Sekhon, H. S., and Quareshi, T. K. (2016), "Role of trusting beliefs in predicting purchase intentions", International Journal of Retail \& Distribution Management, Vol. 44 No. 8.

Schröder, C. (2015), The replication of retail fashion formats into foreign countries: A qualitative analysis. Wiesbaden: Springer.

Shankar, V., Smith, A.K. and Rangaswamy, A. (2003). "Customer satisfaction and loyalty in online and offline environments", International Journal of Research in Marketing, Vol. 20 No. 2, pp. $153-175$.

Sirdeshmukh, D., Singh, J. and Sabol, B. (2002), "Consumer trust, value, and loyalty in relational exchanges", Journal of Marketing, Vol. 66, pp. 15-37.

Srinivasan, S.S., Anderson, R. and Ponnavolu, K. (2002), "Customer loyalty in e-commerce: an exploration of its antecedents and consequences", Journal of Retailing, Vol. 78 No. 1, pp. 41-50.

Sun, P.C. and Lin, C.M. (2010), "Building customer trust and loyalty: An empirical study in a retailing context”, The Service Industries Journal, Vol. 30 No. 9, pp. 1439-1455. 
Swoboda, B., Berg, B., Schramm-Klein, H. and Foscht, T. (2013), "The importance of retail brand equity and store accessibility for store loyalty in local competition", Journal of Retailing and Consumer Services, Vol. 20 No. 3, pp. 251-262.

Thomson, M., MacInnis. D.J. and Park, W.C. (2005), "The ties that bind: Measuring the strength of consumers' emotional attachments to brands", Journal of Consumer Psychology, Vol. 15 No.1, pp. 77-91.

To, P.L., Liao, C. and Lin, T.H. (2007), "Shopping motivations on Internet: A study based on utilitarian and hedonic value", Technovation, Vol. 27 No. 12, pp. 774-787.

Toufaily, E., Ricard, L. and Perrien, J. (2013), "Customer loyalty to a commercial website: Descriptive meta-analysis of the empirical literature and proposal of an integrative model", Journal of Business Research, Vol. 66 No. 9, pp.1436-1447.

Tong, X. (2010), "A cross-national investigation of an extended technology acceptance model in the online shopping context", International Journal of Retail \& Distribution Management, Vol. 38 No. 10 , pp. 742-759.

Van Birgelen, M., de Jong, A. and de Ruyter K (2006), "Multi-channel service retailing: the effects of channel performance satisfaction on behavioral intentions", Journal of Retailing, Vol. 82 No. 4, pp. 367-377.

Van der Heijden, H. (2004), "User acceptance of hedonic information systems", MIS Quarterly, pp. 695-704.

Verhoef, P. C., Kannan, P. K. and Inman, J. J. (2015), "From multi-channel retailing to omni-channel retailing: introduction to the special issue on multi-channel retailing", Journal of Retailing, Vol. 91 No. 2, pp.174-181.

Wallace, D.W., Giese, J.L. and Johnson, J.L. (2004), "Customer retailer loyalty in the context of multiple channel strategies", Journal of Retailing, Vol. 80 No. 4, pp. 249-263.

Yang, Z. and Peterson, R.T. (2004), "Customer perceived value, satisfaction, and loyalty: The role of switching costs", Psychology and Marketing, Vol. 21 No. 10, pp. 799-822. 